\title{
História da Psicologia no Brasil: Uma Narrativa por Meio de seu Ensino ${ }^{1}$
}

\section{History Of Psychology In Brazil: \\ A Narrative From Its Teaching}

Historia De La Psicología En El Brasil:

Una Narrativa Por Medio De Su Enseñanza
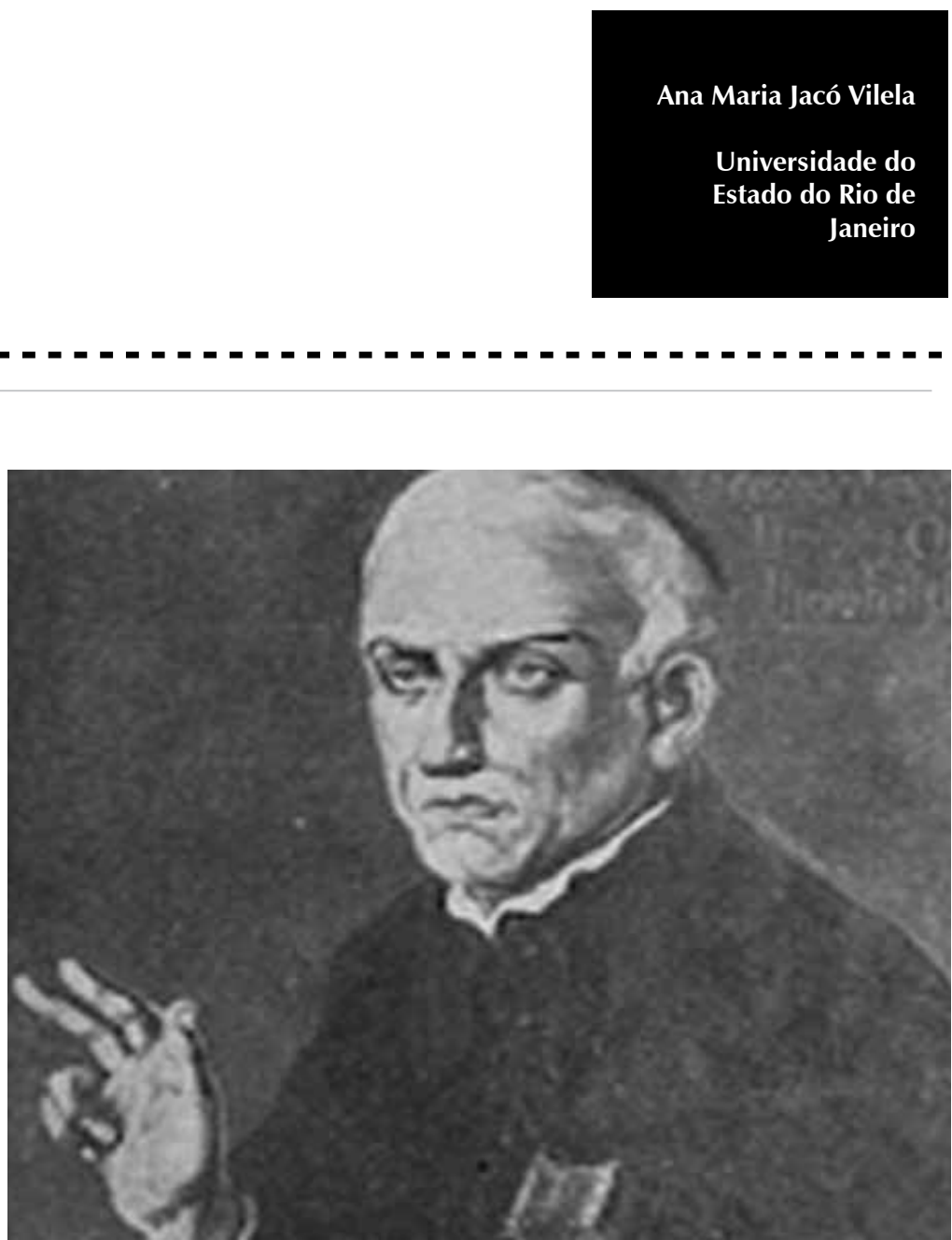
Resumo: O texto pretende apresentar uma história da Psicologia no Brasil relacionando-a às tramas de períodos históricos vividos pelo País, procurando mostrar, em cada um deles, como ocorreu o ensino e a difusão dos saberes psi. Nesse sentido, faz a opção por uma história local, ou história nativa, pois, como Certeau aponta, reconhece a particularidade do lugar de onde se fala, a partir de que posição - social ou geográfica - o pesquisador se pronuncia. O texto tem, pois, um caráter ensaístico, e é um subproduto de leituras e pesquisas sobre a história da Psicologia no Brasil. O texto parte do Brasil colônia e do ensino jesuítico, desenvolvido nos seminários e nos colégios e difundido principalmente através de pregações, explora as teses de Medicina no século XIX, ao mesmo tempo produto do ensino e difusão do conhecimento psicológico entre nós, detém-se nos manuais de Psicologia voltados para as Escolas Normais e ressalta a importância da Biblioteca de Educação no sentido de divulgar a Psicologia nos anos 30. Finalmente, discorre sobre as primeiras obras voltadas para o ensino de Psicologia nos recém-criados cursos nos anos 1950 a 1970 e sobre as formas de difusão do novo campo do saber em um momento já de institucionalização.

Palavras-chave: História da Psicologia - Brasil. Ensino Superior. Ensino da Psicologia. Educação.

Abstract: The text aims to present a history of psychology in Brazil related to the plots of the historical periods experienced by the country, trying to point out how the psychological knowlegde was taught and disseminated. In this sense, chooses a local history, or native history to, as Certeau points out, recognize the particularity of the place where it comes from, and the point of view - social or geographical - under which the researcher speaks. The text has therefore an essayistic character and is a subproduct of readings and research about the history of psychology in Brazil. Part of colonial Brazil and the jesuit teaching, developed in seminaries and colleges and spread primarily through preaching, explores the theses of medicine courses in the nineteenth century, which are at the same time product of education and dissemination of the psychological knowledge among us; it is also presented in Psychology books directed to Normal Schools and points out the importance of the Education's Library disclosure of Psychology in the 30s. Finally, it discusses the early work that is focused on the teaching of psychology in the newly created courses in the years 1950 to 1970 and on the ways of spreading the new field of knowledge at a time when the institutionalization of the field was already driven.

Keywords: History of Psychology - Brazil. Higher education. Psychology Education. Education.

Resumen: El texto pretende presentar una historia de la Psicología en el Brasil relacionándola a las tramas de períodos históricos vividos por el País, procurando mostrar, en cada uno de ellos, como ocurrió la enseñanza y la difusión de los saberes psi. En ese sentido, opta por una historia local, o historia nativa, pues, como Certeau apunta, reconoce la particularidad del lugar de donde se habla, a partir de qué posición - social o geográfica - el investigador se pronuncia. El texto tiene, pues, un carácter ensayístico, y es un subproducto de lecturas y pesquisas sobre la historia de la Psicología en el Brasil. El texto parte del Brasil colonia y de la enseñanza jesuítica, desarrollada en los seminarios y en los colegios y difundida principalmente a través de sermones, explora las tesis de Medicina en el siglo XIX, al mismo tiempo producto de la enseñanza y difusión del conocimiento psicológico entre nosotros, se tienen en los manuales de Psicología dirigidos para las Escuelas Normales y resalta la importancia de la Biblioteca de Educación en el sentido de divulgar la Psicología en los años 30. Finalmente, discurre sobre las primeras obras destinadas para la enseñanza de Psicología en los recién creados cursos en los años 1950 a 1970 y sobre las formas de difusión del nuevo campo del saber en un momento ya de institucionalización.

Palabras clave: História de la Psicología - Brasil. Educación superior. Ensenanza de psicología. Educación.

1 Versão preliminar desse texto foi apresentada no VIII

Encontro Nacional da ABEP, em Goiânia, 2011.
Meu interesse pela história da Psicologia emergiu de um lugar muito específico, o da formação de psicólogos e da consequente preocupação com o caráter centrado em modelos europeus e estadunidenses dessa formação, em que impera o valor intimista, do indivíduo livre, autônomo. A história da Psicologia pareceu-me um excelente dispositivo que, historicizando os diferentes seres humanos estudados pelos saberes psi através dos tempos, permitiria a desnaturalização de nossas ideias e práticas.

Foi estudando a história da Psicologia no Brasil e seus diferentes desenvolvimentos, as abordagens diversas dadas pelos (ainda) poucos autores que se dedicam a essa temática, que fui fazendo algumas escolhas do caminho a seguir. Por um lado, Certeau (1988) logo veio servir de guia ao alertar sobre 
a importância de se demarcar, na escrita da história, o lugar de onde se fala, de onde a narrativa é construída. Tal explicitação compreende desde o porquê da escolha de determinadas abordagens e métodos até a inserção institucional, as redes constituídas, os objetivos e os propósitos da investigação.

Por outro lado, é comum entre os historiadores a noção de que o fato histórico não existe per se, mas é construído retrospectivamente a partir de abordagens diversas, como, por exemplo, a da proveniência (as condições culturais, econômicas, sociais, políticas) que possibilitou sua emergência, que ocorresse tal acontecimento e não outro (Jacó-Vilela, 2009). Embora essa perspectiva esteja presente em quase toda a historiografia atual das ciências, a meu ver, especialmente o estudo da história da ciência em países periféricos coloca necessariamente em cena questões políticas, de dependência, de autonomia ou de colaboração e intercâmbio em relação ao centro, entendido aqui como alguns países da Europa e os Estados Unidos. E esse é o segundo ponto que consideramos importante, a questão de se fazer ciência em um país periférico.

Países europeus colonizaram novos mundos, no processo que perdurou do século XV ao XIX. Nesse percurso, a cultura europeia expandiuse para outros continentes, incluindo, no que aqui nos interessa, a universalização do conceito de ciência, de seus métodos e modelos. Diversos autores vêm alertando, já há algum tempo, que a recepção de novas ideias e práticas em contextos diferentes daqueles em que foram produzidas não é necessariamente ou, pelo menos, não o é na quase totalidade dos casos, uma reprodução daquilo que foi construído em outro lugar (ver, por exemplo, Restrepo Forero, 2000). Tratase, como já afirmava Schwarz, em 1977, de "ideias fora do lugar", e que, por isso mesmo, são apropriadas e se transformam em outras ideias em sua nova ambiência.
Schwarz segue, nesse ponto, uma linha de interpretação da cultura brasileira que se baseia nas contradições e nas ambiguidades existentes nas relações entre senhores e escravos, senhores e homens livres (os agregados) e homens livres e escravos, recorrendo às condições de formação da sociedade brasileira para explicar o seu modo de funcionamento atual.

Da mesma forma o faz Sanchis (1995, 2001). Embora dirigindo-se especificamente ao sincretismo religioso, suas conclusões podem ser estendidas também à produção científica. Sanchis compara o sincretismo religioso brasileiro com o europeu: enquanto este último foi sempre um apagamento da religião anterior (a religião romana utilizando-se das práticas celtas, mas destruindo a lembrança da religião celta, a religião católica fazendo o mesmo com a religião romana), no caso brasileiro o sincretismo significa uma mistura, a preservação de elementos de todas as religiões envolvidas. Sanchis considera as bandeiras como origem desse tipo especial de sincretismo, quando portugueses, tupis e africanos se encontravam em lugares desconhecidos, enfrentando não sabiam que perigos e orando, juntos, para seus deuses particulares.

Esses autores brasileiros representam, pois, uma contribuição à atual discussão no campo da história da ciência acerca da pertinência de se dedicar mais atenção ao que vem sendo denominado ciência nativa, visto um dos temas principais dessa nova historiografia referir-se às formas de recepção, pelos países periféricos, das ideias e práticas geradas nos países centrais que se configuram, então, como novas produções.

Este texto pretende apresentar uma história da Psicologia no Brasil norteada pelos períodos históricos vividos pelo País e procura apontar, em cada um deles, como ocorreu o ensino e a difusão dos saberes psi. Nesse sentido, faz 
Enquanto o

Estado português organizava a nova possessão através das famigeradas capitanias hereditárias, que geraram os latifúndios da cana de açúcar e os territórios de exploração de ouro e pedras preciosas, os jesuítas se dedicavam à catequese dos índios, pois reconheciam neles

"entendimento, memória e vontade", os atributos tomistas da alma (Massimi, 2006). a opção por uma história local, ou história nativa, pois, como Certeau (1988) destaca, reconhece a particularidade do lugar de onde se fala, a partir de que posição - social ou geográfica - o pesquisador se pronuncia. Assim, também utilizando uma expressão desse autor, faremos mais um voo de pássaro por uma floresta, sem nos atentarmos a diferentes detalhes que o olhar atento a uma árvore nos propiciaria. E utilizaremos de autores diversos que se dedicaram a estudar profundamente alguns temas que aqui mencionamos.

\section{O período colonial e o ensino religioso}

O Brasil ingressou no universo europeu em 1500 , quando as primeiras naus portuguesas chegaram ao que hoje constitui parte do seu território. Apesar de disputas com franceses e holandeses, mas principalmente com espanhóis, países desejosos de expandir suas colônias d'além-mar, Portugal manteve sua dominação sobre boa parte do atual território brasileiro durante três séculos. Exerceu-a de forma bem diferente da que a Espanha adotou no restante da América Latina: embora também voltado para a exploração de recursos minerais, cerceou quaisquer atividades relativas à formação cultural do povo colonizado (Fausto, 1995). Uma exceção foram os colégios religiosos, principalmente os dos jesuítas.

Enquanto o Estado português organizava a nova possessão através das famigeradas capitanias hereditárias, que geraram os latifúndios da cana de açúcar e os territórios de exploração de ouro e pedras preciosas, os jesuítas se dedicavam à catequese dos índios, pois reconheciam neles "entendimento, memória e vontade", os atributos tomistas da alma (Massimi, 2006). Ao mesmo tempo, criam colégios para os curumins. O ensino do que hoje denominamos "ideias psicológicas", uma psicologia embasada na Filosofia e na teologia, principalmente a tomista, ocorre nos seminários. O foco principal é tanto o entendimento sobre o homem quanto o objeto da catequese, os curumins, criando-se, pois, uma psicologia infantil. Um importante livro da época é o de Alexandre de Gusmão (1689/2004): A arte de bem educar os filhos na idade da puerícia. O livro abarca os valores morais e religiosos que a família e os professores devem transmitir ainda na primeira infância. Preocupado com o desenvolvimento da criança, Gusmão não desvincula vida familiar, educação, humanismo e coroa portuguesa. Cria uma trama, como diz Oliveira:

O ensino da primeira infância no Tratado revela um arcano que tece teias de relações dos indivíduos entre si, mostrando vários níveis e vários preceitos da forma de educar. As estruturas estão entrelaçadas e enraizadas na cultura humanista. Como esteio do Tratado, encontramos no Ratio Studiorum interconexões que nos levam a entender a vida colonial. Para Gusmão, a arte de educar baseia-se na boa criação, e tanto os pais quanto os professores são tributários desse processo. O conjunto de práxis na educação (trans)forma um campo da pedagogia como uma maneira e razão de ligação dos homens entre si, tudo para o bem da República (2008, p. 8)

Essa forma de divulgação, contudo, está destinada aos eruditos, aos próprios professores, aos jesuítas. A difusão do pensamento religioso e do conhecimento psicológico que se obtém através da observação atenta dos curumins ocorre por meio da pregação (Massimi, 2005): a palavra é instrumento mais contundente na conversão das almas que o texto escrito. Como nos diz Hadot, falando da filosofia antiga:

True education is always oral because only the spoken work makes dialogue possible (...) A number of philosophers (...) thinking, as did Plato and whithout doubt correctly, that what is inscribed in the soul by the spoken word is more real and lasting than letters drawn on papyrus or parchment (1990, p. 498) 


\section{O oitocentos brasileiro - o bando de ideias novas}

Se o Brasil colônia parece estável e perene, apesar de diversas revoltas - a mais famosa sendo a Inconfidência Mineira - o século XIX se inicia sob outros ventos. A família real portuguesa, encabeçada pelo Príncipe Regente, depois Rei Dom João VI, obrigada a abandonar Portugal devido à iminente invasão do País pelas tropas de Napoleão, refugiou-se em sua longínqua colônia. Sua chegada, em 1808, foi um divisor de águas, o estopim para a emergência de uma nova possibilidade de país: com a vinda da Corte, finalmente foi possível a existência de imprensa, de comércio com outras nações, de criação de instituições de nível superior, etc. (Fausto, 1995; Scharcwz, 1993).

Esses acontecimentos não se refletem em transformações imediatas nos modos de vida dos brasileiros. Para tal, serão necessários os vários movimentos políticos do século XIX (a Independência, em 1822, a abolição da escravatura, em 1888, a proclamação da República, em 1889), que se fazem acompanhar por outros - também políticos, como as rebeliões que ocorrem em vários pontos do País ou, ainda, literários, como o romantismo e sua vertente nacional, o indigenismo. O Império se esforça para construir uma identidade nacional, para a qual investe no conhecimento demográfico e cartográfico do País, cria o Instituto Histórico e Geográfico Brasileiro (1838) e incentiva a construção de uma memória nacional - através, por exemplo, de pinturas dos grandes feitos nacionais (como os quadros $A$ Primeira Missa no Brasil, de Victor Meirelles, de 1861, e O Grito do Ipiranga, de Pedro Américo, de 1888). As práticas civilizatórias trazidas pela Corte vão se ampliando e rapidamente o Estado imperial se consolida, com várias "dimensões da experiência pessoal dos cidadãos (sendo) gerenciadas ou controladas diretamente pelo aparelho estatal" (Massimi, 1990, p. 29).

Assim, é possível surgir uma classe média intelectualizada (a chamada Geração de 70), que orienta seus discursos com as palavras de ordem abolição, república e democracia (Herschmann \& Pereira, 1994, p. 22). Embora represente um segmento ínfimo da população, esse grupo, por suas origens de classe e pela valoração que o letrado sempre teve na realidade brasileira, propicia o aparecimento de um projeto igualitário, ao mesmo tempo em que se mantém o modelo hierárquico de sociedade, exemplificando o que Schwarz (1977) denomina "ideias fora do lugar".

Novas maneiras surgem para interpretação da vida brasileira, tendo como ponto comum a ideia de ciência:

Os processos utilizados para o estudo biológico
serviriam também para o estudo psicológico
e sociológico. Daí uma vasta literatura, não
de ciência propriamente, mas de divulgação
ou de especulação científica cujo principal
objetivo era uma explicação elementarista
do homem e da sociedade. (...) Foi essa
literatura de divulgação que se difundiu no
Brasil, e é ela que, em grande parte, explica
o uso - e o abuso - do conceito de ciência
(...). Como para os autores europeus que
imitavam, ciência era frequentemente uma
palavra prestigiosa, capaz de garantir a
verdade do que afirmavam. Outras vezes,
era um programa que propunham, embora
não tivessem recursos para cumpri-lo (Leite,
1969, p. 180)

Vemos, portanto, que diversos aspectos se unem aqui: uma geração de intelectuais com menor vínculo com os grandes proprietários de terras, a oligarquia agroexportadora, a presença das ideias liberais e a divulgação do conhecimento científico. Esse último ponto, como a citação de Dante Moreira Leite, acima, já indica, não é de menor importância: pode-se entender que o cientificismo oitocentista eleva a ciência à posição ocupada anteriormente pela cosmogonia e pela filosofia religiosas, convertendo-a em uma 
nova metafísica. No caso do Brasil, esse processo de hegemonização da ciência recebe um grande suporte com a chegada do positivismo.

Se as produções sobre a alma advêm principalmente do clero, a nova ciência é uma construção dos médicos, normalmente filhos de grandes latifundiários, com algum tipo de formação na Europa - no início, sobretudo na França -, de onde voltam imbuídos de "um bando de ideias novas" (Romero, 1926): evolução, materialismo, progresso, positivismo, ciência e, por que não? Psicologia. São eles principalmente os especialistas que ocupam o lugar dos literatos. A Geração de 70 havia iniciado o entusiasmo pela ciência e, com ele, pelo progresso, pela evolução, pela mudança.

Em sua chegada a Salvador, Dom João VI havia criado a Escola de Cirurgia da Bahia e, logo em seguida, ao chegar ao Rio de Janeiro, a Escola Anatômica, Médica e Cirúrgica do Rio de Janeiro. Estas sofrem diferentes alterações curriculares, instalamse em diversos locais e, em 1832, são transformadas em Faculdades de Medicina. Nesse momento, institui-se a obrigatoriedade de defesa de teses para a obtenção de título de Doutor em Medicina, prática que perdura até 1932. Aqui encontramos ainda a presença do discurso católico que, aos poucos, vai sendo substituído pelo discurso científico. Já em 1841, na Faculdade de Medicina do Rio de Janeiro, Antonio Pereira D'Araújo Pinto apresentava uma tese sobre frenologia, a doutrina criada por Gall ao final do século XVIII que procurava estabelecer a localização cerebral das diferentes faculdades humanas: "para cada faculdade especial, para cada instinto primitivo, para cada sentimento particular, há no cérebro um órgão próprio, uma circunvolução que, pela sua proeminência, se revela na forma exterior do crânio" (Gonçalves de Magalhães, 1876, p. 10).
Assim, com o prestígio das ciências naturais e biológicas e do evolucionismo de Darwin, o homem pode ser estudado como um organismo, da mesma forma que os outros seres vivos. Perde-se a unidade entre corpo e alma; esta deve ser conhecida através daquele, principalmente através da fisiologia do cérebro, órgão onde se localizam as propriedades e funções da alma. Como a ciência implica regularidades mensuráveis, o conhecimento não é mais produto da autorreflexão, do voltar-se da alma para si mesma. No movimento das ideias psicológicas, podemos então apontar um segundo tempo, um tempo do organismo, um discurso do corpo (Keide e Jacó-Vilela, 1999): a alma do discurso religioso colonial é progressivamente objetivada, agora pelo discurso da ciência. O que se conhece são os produtos de um funcionamento interno que, ele próprio, não podendo ser percebido pelo sujeito, só pode ser conhecido pelo outro através de mensurações.

Nas Faculdades de Medicina, o ensino é feito principalmente através de livros importados e da sapiência dos professores catedráticos, normalmente experts em alemão e francês, os principais idiomas da época. É interessante observar, nas teses da Faculdade de Medicina do Rio de Janeiro, o quanto o conhecimento psicológico desenvolvido na Europa e nos Estados Unidos chega rápido e é citado, muitas vezes de forma complementar, a autores de outras origens. Encontramos com frequência a mençao a autores da psicologia alemã, principalmente Wundt - "É a Wundt que a psychologia experimental deve os seus mais bellos florões" (Roxo, 1900, p. 15) - embora Humbolt e Fechner também sejam citados. A psicologia francesa, sem dúvida, é a mais assídua, não tanto Ribot, mas principalmente Charcot, Pierre Janet e a Escola de Nancy, que estão presentes nas teses sobre histeria e hipnotismo, como as de Fajardo Júnior (1889) e de Ribeiro (1886). A antropologia criminal, de Lombroso, também se fará presente, com 
2 Ver, a respeito, a excelente análise do pensamento social brasileiro efetuada por Dante Moreira Lima (1954/1969). É importante ressaltar também a exceção representada por Manoel Bomfim (1868-1932), em seu livro A América Latina: males de origem (1905/1993).

Bomfim não só é uma voz dissonante no discurso racialista de sua época como estabelece laços fraternos entre os países latinos, ao propor uma explicação psicossocial para a diferença entre o desenvolvimento europeu e o latino: a colonização parasitária realizada pelos países ibéricos. as noções de estigmas físicos (Corrêa, 1905) enquanto a teoria da degenerescência de Morel é uma constante (Corrêa, 1905; Velho, 1905). Destaque, todavia, deve ser dado à tese intitulada Duração dos atos psíquicos elementares nos alienados, de Henrique Roxo, primeiro trabalho de Psicologia experimental realizado e publicado no Brasil (1900). Roxo mede o tempo de reação dos internos no Hospício Nacional de Alienados utilizando-se, para isso, do psicômetro de Buccola, um instrumento hoje desconhecido.

As teses são, pois, resultado de um processo de ensino e, ao mesmo tempo, fator de difusão do novo conhecimento psicológico. Não à toa, são investigadas até hoje, não só por pesquisadores da Psicologia como também por pesquisadores de outras áreas, como Educação, Educação Física, Arquitetura, Nutrição, além da própria Medicina. São elas, sem dúvida, que criam, em solo brasileiro, o hábito de produção de textos, que, muitas vezes, são ambivalentes e contraditórios, mas constituem uma forma própria de se apropriar daquele bando de ideias que vêm fervilhar em um país agrário, de matriz conservadora, escravagista, religioso, defensor da hierarquia entre os homens e da superioridade da raça branca. É necessário conciliar contrários, e os médicos se encarregam de sanear a nação com tais conhecimentos.

\section{Um período turbulento. A educação como resposta}

As novas ideias demonstraram, entre outras coisas, que o País estava doente: povoado por uma população inculta, que habitava centros urbanos longe dos graus mínimos de civilidade europeia, era necessário higienizar as cidades, os corpos e as mentes (Schwarcz, 1993; Herschmann \& Pereira 1994). Esse é o esforço a que se dedicam os intelectuais na Primeira República - médicos, juristas, literatos, todos estão interessados em elevar o País a um patamar que o afaste de suas origens viciosas - aqui consideradas, pela maioria dos autores da época, como a herança africana e, em menor grau, a indígena ${ }^{2}$. Trata-se de uma geração de intelectuais que pretendiam "reinventar o País, organizá-lo em novas bases, fazê-lo transpor rapidamente as enormes barreiras arcaicas que o separavam da civilização contemporânea" (Campos, 2002, p. 24).

Coube, pois, aos intelectuais engajados na causa republicana a reforma do Estado para superar os desafios de um país que viam como atrasado econômica e culturalmente e conduzi-lo ao modelo civilizado de uma nação europeia. Nesse sentido, considerase que a redução e/ou eliminação do analfabetismo seja fundamental. Estima-se que em torno de $65 \%$ da população brasileira era analfabeta em princípios do século XX, em contraposição, por exemplo, à situação argentina, em que parcela relevante da população era alfabetizada em função não só dos esforços civilizatórios como também da imigração selecionada de meados do século XIX (Fausto \& Devoto, 2004).

A elite política e intelectual dedica-se à educação. No ano seguinte à proclamação da república, nova legislação modifica o sistema de ensino (Brasil, 1890), pois observa-se que a educação é deficitária, no sentido de ser arcaica, artificial, baseada na memorização e nos castigos físicos (Gondra, 2004), com pouco conteúdo das novas ciências.

É nesse contexto que surgem as primeiras propostas de educação, concretizadas naquela legislação citada acima, conhecida como Reforma Benjamim Constant, e que levam à criação do Pedagogium, museu pedagógico ao estilo dos existentes em diversos países europeus e cuja direção será ocupada por Manoel Bomfim, médico que abandona a carreira e se dedica à educação. 
No Pedagogium, Bomfim cria, em 1906, aquele que é reconhecido como o primeiro Laboratório de Psicologia Experimental no País. Certamente outros laboratórios já existiam, embora de forma menos institucionalizada, pois, como dissemos, Henrique Roxo produz uma tese resultante de trabalho experimental, em 1900, e Lourenço Filho registra a proposta de criação de um laboratório no Rio de Janeiro, em 1897, anotando também a reação de um dos opositores da ideia: "Seria ridículo pretender levar as faculdades da alma à análise de aparelhos" (Lourenço Filho, 1955/2004, p. 74).

Mas, para que a educação frutifique, é necessário que o terreno seja fértil. Assim, os intelectuais se dedicam à prevenção, seja pelo sanitarismo - a limpeza da cidade -, seja pela higiene mental. A Liga Brasileira de Higiene Mental, criada por Gustavo Riedel no Rio de Janeiro, em 1923, tem destacados membros da elite médica e intelectual entre seus filiados. Muitos personagens relevantes na história da Psicologia brasileira ocupam posições em seus quadros, como: Plinio Olinto, professor de Psicologia na Escola Normal, responsável pelo Serviço de Psicologia, do qual farão parte Maria Brasília Leme Lopes e Idalina de Abreu Fialho; Ulisses Pernambucano, representante da Liga em Pernambuco; Manoel Bomfim, professor Catedrático de Psicologia na Escola Normal, que se encontra na Seção de Deficiência Mental; Maurício de Medeiros, professor de Psicologia da Escola Normal, está na Seção de Medicina Legal, Indigência e Vadiagem (Archivos Brasileiros de Higiene Mental, 1925).

Consideramos importante resgatar a presença desses nomes na Liga porque raramente é mencionada a estreita relação da Psicologia com o higienismo, como se esse fosse um fato vergonhoso na história da área. Entretanto, o movimento higienista aparece com um caráter missionário, progressista, de melhoria das condições de vida das camadas mais pobres da população. Assim, pela análise da história de vida e de compromissos de muitos dos participantes da Liga, era quase uma impossibilidade afastar-se do pensamento higiênico naquele momento. Isso é diferente da década de 30, quando a Liga assume um caráter eugênico e muitos dos personagens que citamos dela se retiram. Ulisses Pernambucano, por exemplo, simplesmente separa a Liga de Pernambuco da Liga Brasileira.

É conveniente, no entanto, lembrar a importante contribuição da Liga para a produção e a disseminação do conhecimento em Psicologia, em uma seara que havia surgido no começo do século na Europa e que somente nos anos 20 e 30 se desenvolverá no Brasil: os testes psicológicos. São muitas as publicações nos Archivos Brasileiros de Higiene Mental sobre esse tema, enfatizando principalmente a necessidade de estandardização dos testes para a realidade brasileira (Leme Lopes, 1930; Leme Lopes, 1932; Lopes, 1931). Um artigo interessante a esse respeito é de autoria de Ulisses Pernambucano e Anita Barreto: os autores relatam seus esforços para a adaptação do teste de Ballard à realidade pernambucana e o intercâmbio realizado com Helena Antipoff, que estava fazendo a mesma adaptação em Belo Horizonte: os três visavam a tradução mais adequada de determinadas palavras (Pernambucano \& Barreto, 1931).

Se os Archivos são úteis para difundir os testes, sem dúvida, o instrumento que permitirá a visibilidade da prática psicológica, o ensino de Psicologia ocorrerá principalmente nas Escolas Normais, visando à formação das futuras professoras primárias. Ele será baseado nas aulas dos professores, que continuam autodidatas, experts em idiomas estrangeiros, dentre os quais o inglês inicia a sua participação. Mas começam a ser publicados manuais voltados para o ensino de Psicologia nas Escolas Normais, o que 
podemos considerar como os primeiros trabalhos verdadeiramente didáticos em Psicologia. Na década de 20, encontramos dois, versando ainda sobre testes. O mais famoso deles, por ser o primeiro e pelo impacto que causa, é de Medeiros e Albuquerque, publicado em 1924 e intitulado Tests, grafado em inglês, comprovação da recenticidade do tema no País; o de Manoel Bomfim, intitulado O Método dos Tests, é de 1928. Neste há somente um capítulo sobre testes psicológicos, pois Bomfim dedica-se prioritariamente aos testes pedagógicos e à explicação sobre como construir um bom teste. Entretanto, ele já publicara, em 1916, o Noções de Psychologia, um manual em que trata de temas como sensação, linguagem, juízo, personalidade, desenvolvimento, etc., com uma abordagem didática e centrada na importância das relações sociais.

A década de 20 também é reconhecida, no Brasil, como um período de efervescência político-cultural, com vários acontecimentos de ordens diversas. Diferentemente do começo do século XX, em que a República é embrionária e em que os sonhos são possíveis, nos anos 20, o clima é de crítica ao modelo republicano oligárquico existente. Há revoltas, como a tenentista, que visam à transformação do regime político e da qual decorre a Coluna Prestes. Há movimentos de renovação cultural, como o modernista. Há a fundação do Partido Comunista do Brasil (1922), e é esse também um momento de crise da cafeicultura e, portanto, de dificuldades econômicas para o País. É quando a Igreja Católica se reorganiza e aglutina seus intelectuais em torno do Centro Dom Vital, criado em 1922, visando a retomar sua hegemonia entre a intelectualidade contaminada por aquelas ideias novas materialistas, evolucionistas, etc. O governo Arthur Bernardes (1922-1926) transcorre quase todo sob estado de sítio, demonstrando os diferentes descontentamentos com o regime oligárquico e com a chamada política do café-com-leite (a alternância na Presidência da República entre paulistas e mineiros). Tudo isso acaba desembocando na Revolução de 1930 e no Governo Provisório, com Getúlio Vargas no poder, o que se prolonga por 15 longos anos, metade dos quais sob a forma ditatorial (Fausto, 1995).

Para a educação, contudo, há mudanças positivas. Com a centralização administrativa do Governo Vargas, a regulamentação do estatuto das universidades, a força que adquire a Associação Brasileira de Educação (fundada em 1924) com o Manifesto dos Pioneiros da Educação (1932) e a criação do primeiro curso de Pedagogia (em 1935, na Universidade do Distrito Federal, de curta duração; em 1939, na Universidade do Brasil), a criança entendida como o futuro da Nação, a Educação se torna projeto de Estado.

Neste projeto, a Psicologia ocupa um espaço diferenciado, porque, no dizer de Lourenço Filho, é "uma das bases da educação" (Lourenço Filho, 1930/2002). Assim, nada mais justo que, na coleção Biblioteca de Educação, dirigida pelo próprio Lourenço Filho para a Editora Melhoramentos, livros de Psicologia tenham uma forte presença. Segundo Monarcha (1997), são publicados 36 títulos entre 1927 a 1941, mas "a fase áurea da coleção - 1927 a 1930 corresponde aos anos de organização e de impacto do projeto editorial, tendo sido publicados 12 títulos" (1997, p. 29). Reproduzimos abaixo esses títulos para comprovar a relevância da Psicologia para o esforço da educação e para justificar a expressão de Lourenço Filho citada acima (na verdade, uma das subdivisões de seu livro presente na coleção). Vemos também a tradução de importantes autores, principalmente três de grande relevância na Psicologia francesa - Piéron, Binet e Simon-, 
além do genebrino Claparède, uma unanimidade internacional à época, e livros de autores brasileiros, que Monarcha informa serem "autores paulistas".

Tabela 1. Livros Publicados na Coleção Biblioteca da Educação (1927-1930)

\begin{tabular}{lll}
\hline Piéron & Psychologia experimental & 1927 \\
Claparède & A escola e a psychologia experimental & 1928 \\
Sampaio Dória & Educação moral e educação econômica & 1928 \\
Geenen & $\begin{array}{l}\text { Temperamento e caráter sob o ponto } \\
\text { de vista educativo }\end{array}$ & 1928 \\
Durkheim & Educação e sociologia & 1928 \\
Firmino de Proença & Como se ensina geografia & 1928 \\
Domingues & Hereditariedade em face da educação & 1929 \\
Fonseca & A escola activa e os trabalhos manuaes & 1929 \\
Ferriére & A lei biogenética e a escola ativa & 1929 \\
Binet e Simon & Testes para a medida do & \\
& desenvolvimento da inteligência nas & 1929 \\
crianças & \\
Lourenço Filho & Introdução ao estudo da Escola Nova & 1930 \\
Dewey & Vida e educação & 1930 \\
\hline
\end{tabular}

Fonte: Monarcha, C. Lourenço Filho: outros aspectos, mesma obra. 1997.

Outras editoras também começam a publicar obras de Psicologia. Ainda são em pequeno número, normalmente livros inseridos em coleções destinadas à educação, como a Atualidades Pedagógicas, da Companhia Editora Nacional. Nas Faculdades de Filosofia e em outras Faculdades, como a de Educação Física da Universidade do Brasil, surgem as cátedras de Psicologia, o que favorece o mercado editorial, pois o ensino de Psicologia não se restringe mais às Escolas Normais.

\section{A industrialização, a modernização, enfim, a Psicologia tout court}

O Governo Vargas impulsiona a industrialização com a criação de empresas estatais como a Companhia Siderúrgica Nacional (1941), a Companhia Vale do Rio Doce (1942), a Fábrica Nacional de Motores (FNM, 1942), a Companhia Nacional de Álcalis (1943) e a Companhia Hidrelétrica do São Francisco (1945). Esse projeto de industrialização, denominado substituição de importações, será acelerado no Governo Juscelino Kubitscheck, durante os famosos "50 anos em 5" cujo símbolo é a construção de Brasília. O Plano de Metas desse Governo implica uma urbanização crescente e forte desenvolvimento industrial, o que acentua a desigualdade entre os mundos rural e urbano. É importante ressaltar, contudo, que o desenvolvimento das telecomunicações, se fora iniciado experimentalmente com o rádio, nos anos 20, só foi desenvolvido de fato no Governo Vargas; a televisão, por sua vez, surge nos anos 50, mas só será expandida na ditadura militar dos anos 70 .

No campo do ensino, surgem os primeiros cursos de especialização em Psicologia. A principal instituição a oferecê-los é o Instituto Sedes Sapientiae, de São Paulo, sob a direção combativa 
e eficaz de Madre Cristina (1916-1997). No Rio de Janeiro, o Instituto de Seleção e Orientação Profissional da Fundação Getúlio Vargas (ISOP/FGV), criado em 1947 sob a direção de Emilio Mira y López (18961964), oferece inúmeros cursos de extensão. Mira y López é um divulgador constante da Psicologia, através de conferências e artigos em jornais diários (Rosas, 1997) e sua presença é, sem dúvida, relevante para os acontecimentos dos anos 1940 a 1960 na Psicologia brasileira.

Aqui encontramos explicitamente a atuação profissional do psicólogo, chamado às vezes de psicotécnico ou de psicologista. Não mais subsumido sob o mando da educação, o profissional do final dos anos 40 em diante está no campo da seleção e da orientação profissional, como no ISOP (ou na Estrada de Ferro Sorocabana, em São Paulo, ou ainda no Banco da Lavoura, em Belo Horizonte), está nas escolas, principalmente nas experimentais, e começa a atuar na clínica, realizando psicodiagnóstico infanto-juventil, orientação de pais e mesmo orientação vital. Em todos esses campos, os testes psicológicos serão o instrumental privilegiado para a atuação do novo profissional.

Perguntamo-nos, então: como aprende? Através dos cursos citados acima, através dos estágios, das leituras, dos grupos de estudos. É nesses, por exemplo, que as psicólogas do Centro de Orientação Juvenil, a mais importante clínica pública de atendimento à população infanto-juvenil durante os anos 1940-1970, no Rio de Janeiro, deixam de se restringir ao psicodiagnóstico e se iniciam na psicoterapia de abordagem rogeriana ainda nos anos 50 (Jacó-Vilela, Oliveira, Espírito Santo, Carneiro, Messias, \& Valente, 2007).

As primeiras associações de Psicologia, bem como os primeiros periódicos, são criados na década de 40: a Sociedade de Psicologia de São Paulo (hoje oficialmente
Associação de Psicologia de São Paulo) é fundada em 1945, e seu periódico, o Boletim de Psicologia, surge em setembro de 1949 (Angelini, 2011). A Associação Brasileira de Psicotécnica (hoje Associação Brasileira de Psicologia Aplicada), criada, por sua vez, por técnicos e frequentadores das atividades do ISOP em setembro de 1949, lança, na mesma data, o primeiro número de seu periódico, Arquivos Brasileiros de Psicotécnica - nome alterado para Arquivos Brasileiros de Psicologia Aplicada e, finalmente, para Arquivos Brasileiros de Psicologia (Castro \& Alcântara, 2011). É importante ressaltar que tanto essas associações quanto os periódicos continuam existindo até os dias de hoje.

Entramos, pois, em um período de institucionalização da Psicologia. Não por acaso, em 1953, a PUC-Rio cria seu Curso de Graduação em Psicologia (Feres-Carneiro, 2011), seguida, no ano seguinte, pela PUC-RS (Scarparo, 2011). Está pronto o terreno para que, com cursos recém-criados e com profissionais que atuam no campo, que se intitulam psicólogos, se filiam a associações de Psicologia, escrevem para periódicos de Psicologia, surja o movimento para a regulamentação da profissão e dos cursos. Não é um processo fácil. Cheio de idas e vindas, tem como disparador o pré-projeto de currículo elaborado pela Associação Brasileira de Psicotécnica e publicado nos Arquivos Brasileiros de Psicotécnica em 1954. Rechaçado pela cátedra de Psicologia da Faculdade Nacional de Filosofia da Universidade do Brasil, ocupada por Nilton Campos, bem como pela Sociedade Paulista de Psicologia, devemos reconhecer que propicia as discussões que levam ao projeto finalmente aprovado em 27 de agosto de 1962 como Lei oㅜ 4.119.

Como se situa, então, o ensino de Psicologia? Continua muito parecido com o ensino anterior, só que agora os professores têm formação universitária (em áreas diversas, como Direito, Medicina, Teologia, Economia, 
embora a maioria seja formada em Filosofia ou Educação) e são autodidatas em Psicologia. Entretanto, alguns fazem cursos de Psicologia, em nível de pós-graduação, no exterior. É o caso, por exemplo, de Annita de Castilho e Marcondes Cabral, de São Paulo (com Koffka no Smith College, e com Wertheimer na New School for Social Research, em 1942) e de Eliezer Schneider, do Rio de Janeiro (Yowa University, 1947).

O ensino continua, pois, centrado na expertise do professor. Muitos deles, abnegadamente, traduzem textos estrangeiros para os alunos ${ }^{3}$. Quando estes têm condições, importam/compram livros, principalmente os publicados por editoras argentinas (notadamente a Paidós e a Kapelusz). Mas, aos poucos, o mercado editorial brasileiro, até então voltado para a Psicologia que interessava à educação, descobre os cursos de Psicologia. Nesse sentido, muito devemos a algumas editoras - como a Nacional, a Herder, a Pioneira, a Zahar - bem como a alguns professores, que se dedicaram a traduzir livros básicos, manuais que cobrissem a ampla gama de disciplinas que compunham/compõem a grade curricular do curso de Psicologia. Destes, damos destaque a dois: Dante Moreira Leite e Carolina Martuscelli Bori, pelo volume de traduções que realizaram. Não conseguimos obter uma lista precisa das traduções realizadas por esta última. Assim, colocamos abaixo somente as traduções realizadas por Leite nas décadas de 50 e 60.

Tabela 2. Traduções de manuais de psicologia por Dante Moreira Leite nas décadas de 50 e 60

Asch, S. E. (1960). Psicologia social (D. M. Leite \& M. M. Leite, Trads.). São Paulo: Nacional (Obra original publicada em 1952).

Personalidade: manual para o seu estudo, organizado com leituras básicas de psicologia da personalidade. (1963). (D. M. Leite \& M. M. Leite, Trads.). Biblioteca Universitária; Série Ciências Sociais, no 10). São Paulo: Nacional (Obra original publicada de um número de artigos em inglês). Krech, D., \& Crutchfield, R. S. (1963). Elementos de psicologia (D. M. Leite, Trad.). São Paulo: Pioneira.

Noll, V. H. (1963). Medidas educacionais (D. M. Leite \& M. M. Leite, Trads.). São Paulo: Pioneira. Anastasi, A. (1964). Testes psicológicos: teoria e aplicação (D. M. Leite, Trad., Coleção Ciências do Comportamento). São Paulo: Herder.

Allport, G. W. (1966). Personalidade (D. M. Leite, Trad.). São Paulo: Herder.

Mouly, G. J. (1966). Psicologia educacional (D. M. Leite \& M. M. Leite, Trads.). São Paulo: Pioneira (Obra original publicada em 1963).

Selltiz, C. (1967). Métodos de pesquisa nas relações sociais (D. M. Leite \& M. M. Leite, Trads.). São Paulo: Herder.

Cartwright, D., \& Zander, A. (Orgs.). (1967/1972). Dinâmica de grupo (Vols. 1-2, D. M. Leite \& M. M. Leite, Trads.). São Paulo: Herder.

3 Esta foi minha experiência em minha graduação na UFMG no final dos anos de 1960 e início dos anos de 1970. Neste sentido, este texto é também um tributo tardio à professora Natalia, de meu primeiro ano de Psicologia, que se desdobrava mimeografando traduções para nós.
Morse, W. C., Wingo, G. M. (Orgs.). (1968). Leituras em psicologia educacional (D. M. Leite, Trad., Atualidades Pedagógicas, no 93). São Paulo: Nacional.

O’Dea, T. F. (1969). Sociologia da religião (D. M. Leite, Trad., Biblioteca Pioneira de Ciências Sociais). São Paulo: Pioneira.

Parsons, T. (1969). Sociedades: perspectivas evolutivas e comparativas (D. M. Leite, Trad.). São Paulo: Pioneira.

Krech, D. et al. (1969). O indivíduo na sociedade: um manual de psicologia social (D. M. Leite \& M. M. Leite, Trads.). São Paulo: Pioneira.

Fonte: Centro de Memória do Instituto de Psicologia da USP. Disponível em http://citrus.uspnet.usp.br/ centrodememoriaip/?q=node/326 
Esse foi, pois, um momento de absorção do conhecimento já existente, já produzido, de se assegurar do campo conhecido. Outras coleções e livros individuais aparecerão na década de 70 .

O crescimento da publicação em Psicologia, e sua adoção nos cursos e no ensino, todavia, somente ocorrerá a partir de meados dos anos 80. Diversos fatores desencadearão esse processo: a pós-graduação que, iniciada em 1964, na UnB, e logo abortada, se firma a partir de 1967 com o curso da PUC-Rio, o crescente número de cursos de graduação, a psicologização da sociedade brasileira a partir dos anos 70, como já foi analisado por diversos autores (ver, por exemplo, Figueira, 1981; Duarte, 1986; Russo, 1993), que leva a um interesse cada vez maior pela Psicologia. Começa, então, um processo de reflexão sobre a necessidade de maior conhecimento da realidade brasileira e, em consequência, de produções e de ensino de Psicologia baseados nessa realidade.

Penso ser esse o momento em que ainda nos encontramos. Há, entretanto, uma produção multivariada que gera seu próprio efeito perverso: embora o estudante de Psicologia compreenda - e, aparentemente, aprove - a diversidade da Psicologia, o conhecimento sobre a disciplina é disperso, visto não haver mais a preocupação com um conteúdo mínimo do qual o psicólogo deva dar conta.

\section{Considerações finais}

Como dito inicialmente, meu interesse primordial se situa na formação de psicólogos. Este texto, por sua vez, é um subproduto das diferentes pesquisas que tenho realizado nos últimos anos. É um olhar para trás, que reflete sobre como teria sido ensinar Psicologia quando a disciplina Psicologia não existia, não existiam livros, não existia curso, não existia o profissional psicólogo. É uma tentativa de não reduzir nossa história aos últimos 50 anos e procurar trazer à memória pessoas, livros, processos, dispositivos, enfim, tudo aquilo que tornou possível, em determinadas condições históricas, que pudéssemos agora, em 2012, comemorar uma data - escolhida dentre tantas outras possíveis - na história da Psicologia que se constrói no Brasil. 


\section{Ana Maria Jacó Vilela}

Doutora em Psicologia (USP), com Pós-doutorado em História e Historiografia da Psicologia na Universidade Autônoma de Barcelona. Professora associada da Universidade Estadual do Rio de Janeiro, Rio de Janeiro - RJ. E-mail:amjaco@uol.com.br

Endereço para envio de correspondência:

Rua Dona Mariana 72, apto. 508, Botafogo, Rio de Janeiro - RJ - Brasil. CEP: 22280-020 
Angelini, A. L. (2011). Associação de Psicologia de São Paulo. In A. M. Jacó-Vilela. (Org.), Dicionário Histórico de Instituições da Psicologia no Brasil. Rio de Janeiro: Imago; Brasília, DF: Conselho Federal de Psicologia.

Archivos Brasileiros de Higiene Mental, (1925), 1(1).

Bomfim, M. (1916). Noções de psychologia. Rio de Janeiro: Livraria Escolar.

Bomfim, M. (1928). O methodo dos tests. Rio de Janeiro: (s/e).

Bomfim, M. (1993). A América Latina: males de origem. (4a. ed.). Rio de Janeiro: Topbooks (Trabalho original publicado em 1905).

Brasil. Decreto no. 981, de 8 de novembro de 1890. Approvao Regulamento da Instrucção Primaria e Secundaria do Districto Federal.
Campos, R. H. F. (2002). Prefácio. In M. B. Lourenço Filho. Introdução ao estudo da escola nova. Rio de Janeiro: EdUERJ.

Castro, A. C., \& Alcântara, E. S. (2011). Associação Brasileira de Psicologia Aplicada. In A. M. Jacó-Vilela (Org.), Dicionário Histórico de Instituições da Psicologia no Brasil. (pp. 47-49). Rio de Janeiro: Imago; Brasília, DF: Conselho Federal de Psicologia.

Certeau, M. (1988). A operação histórica. In J. Le Goff \& P. Nora (Orgs.), História, novos problemas (pp. 17-38). Rio de Janeiro: Francisco Alves.

Corrêa, C. A. (1905). Estygmas anatômicos dos degenerados. Tese de doutorado, Faculdade de Medicina, Rio de Janeiro, RJ.

Duarte, L. F. D. (1986). Da vida nervosa das classes trabalhadoras urbanas. Rio de Janeiro: Jorge Zahar; Brasília, DF: CNPq. 
Fajardo Júnior, F. P. (1889). Hipinotysmo. Tese de doutorado, Faculdade de Medicina, Rio de Janeiro, RJ.

Fausto, B. (1995). História do Brasil. São Paulo: Edusp/FDE.

Fausto, B., \& Devoto, F. (2004). Brasil e Argentina: um ensaio de história comparada (1850-2002). São Paulo: Editora 34.

Feres-Carneiro, T. (2011). Departamento de Psicologia da Pontifícia Universidade Católica do Rio de Janeiro (PUC-Rio). In A. M. Jacó-Vilela (Org.), Dicionário Histórico de Instituições da Psicologia no Brasil. (pp.149-150). Rio de Janeiro: Imago; Brasília, DF: Conselho Federal de Psicologia.

Figueira, S. A. (1981). O contexto social da psicanálise. Rio de Janeiro: Francisco Alves.

Gonçalves de Magalhães, D. J. (1876). A alma e o cérebro. Rio de Janeiro: Garnier.

Gondra, J. G. (2004). Artes de civilizar: medicina, higiene e educação escolar na Corte Imperial. Rio de Janeiro: EdUERJ.

Gusmão, A. (2004). Arte de crear bem os filhos na idade da puerícia - dedicada ao Menino de Belém lesus de Nazareno. São Paulo: Martins Fontes (Trabalho original publicado em 1689).

Hadot, P. (1990). Forms of life and forms of discourse in ancient philosophy. Critical Inquiry, Chicago, 16(3), 483-505.

Herschmann, M. M., \& Pereira, C. A. M. (Orgs.). (1994). A invenção do Brasil moderno: medicina, educação e engenharia nos anos 20-30. Rio de Janeiro: Rocco.

Jacó-Vilela, A. M. (2009). Historiografia da psicologia no Brasil. In J. Bernardes \& B. Medrado (Org.), Psicologia social e políticas de existência: fronteiras e conflitos (pp.125-138). Maceió, AL: Ed. Abrapso.

Jacó-Vilela, A. M., Oliveira, F. M., Espírito Santo, A. A. do, Carneiro, F. D., Messias, M. C. N., \& Valente, N. F. (2007) Uma gestação silenciosa: a presença feminina nas instituições de psicologia no Rio de Janeiro na primeira metade do século XX. In M. A. T. Ribeiro \& J. Bernardes (Orgs.), A produção na diversidade: compromissos éticos e políticos em psicologia. (Vol. 1, pp. 231-366). São Paulo: Casa do Psicólogo.

Keide, R., \& Jacó-Vilela, A. M. (1999). "Mens in corpore": o positivismo e o discurso psicológico do século XIX no Brasil. In A. M. Jacó-Vilela, H. C. Rodrigues \& F. Jabur. Clio-Psyché -histórias da Psicologia no Brasil. Rio de Janeiro: Nape.

Leite, D. M. (1969). O caráter nacional brasileiro. São Paulo: Pioneira (Trabalho original publicado em 1954).

Leme Lopes, M. B. (1930). Pesquisas sobre a memória de fixação. Archivos Brasileiros de Higiene Mental, 3(2), 235-240.

Leme Lopes, M. B. (1932). A attenção concentrada explorada pelo test de cancellamento. Archivos Brasileiros de Higiene Mental, 5(2), 41-63.

Lopes, E. (1931). Subsídio para a adaptação brasileira dos tests de Binet-Terman. Archivos Brasileiros de Higiene Mental, 4(3), 180-207.

Lourenço Filho, M. B. (2002). Introdução ao estudo da escova nova. Rio de Janeiro: EdUERJ (Trabalho original publicado em 1930).

Lourenço Filho, M. B. (2004). A psicologia no Brasil. In M. A. P. Antunes. História da Psicologia no Brasil: primeiros ensaios. (Org.). Rio de Janeiro: EdUERJ (Trabalho original publicado em 1955).

Massimi, M. (1990). História da psicologia brasileira - da época colonial até 1934. São Paulo: E.P.U.

Massimi, M. (2005). Palavras, almas e corpos no Brasil colonial. São Paulo: Loyola.
Massimi, M. (2006). Ideias psicológicas na cultura luso-brasileira do século XVI ao século XVIII. In A. M. Jacó-Vilela, A. A. L. Ferreira \& F. T. Portugal (Orgs.), História da Psicologia: rumos e percursos (pp. 75-83). Rio de Janeiro: Nau Editora.

Medeiros \& Albuquerque, J. J. C. C. (1924). Tests. Rio de Janeiro: Livraria Francisco Alves.

Monarcha, C. (Org.). (1997). Lourenço Filho: outros aspectos, mesma obra. Campinas, SP: Mercado de Letras.

Oliveira, F. F. (2008). Alexandre de Gusmão: arte de educar meninos nos bons costumes. Dissertação de mestrado, Pós-Graduação em Educação, Universidade Metodista de Piracicaba, Piracicaba, São Paulo, SP.

Pernambucano, U., \& Barreto, A. P. (1930). Ensaio de applicação do test das 100 questões de Ballard. Archivos Brasileiros de Higiene Mental, 3(9), 313-345.

Pinto, A. P. A. (1841). Algumas proposições de phrenologia. Tese de doutorado, Faculdade de Medicina, Rio de Janeiro, RJ.

Restrepo Forero, O. (2000). La sociologia del conocimiento científico o de cómo huir de la "recepción" y salir de la "periferia". In D. Obregón. (Ed.), Culturas científicas y saberes locales: asimilación, hibridación, resistencia. Bogotá: Universidad Nacional de Colombia.

Ribeiro, E. C. (1886). Perturbações psychicas no domínio da histeria. Tese de doutorado, Faculdade de Medicina, Rio de Janeiro, RJ.

Romero, S. (1926). Explicações indispensáveis. Prefácio a vários escritos de Tobias Barreto de Menezes In T. Barreto, Obras Completas (Vol. X, pp. XXVI, Edição do Estado Sergipe). Rio de Janeiro: Pongetti. (Trabalho original publicado em 1900).

Rosas, P. (1997). Mira y Lopez e a psicologia aplicada no Brasil. Rio de Janeiro: Ed. da FGV.

Roxo, H. B. B. (1900). Duração dos atos psíquicos elementares nos alienados. Tese de doutorado, Faculdade de Medicina, Rio de Janeiro, RJ.

Russo, J. A. (1993). O corpo contra a palavra: as terapias corporais no campo psicológico nos anos 80. Rio de Janeiro: Ed. da UFRJ.

Sanchis, P. (1995). Sincretismo e jogo das categorias: a propósito do Brasil, de Portugal e do Catolicismo. Psicologia Práticas Sociais, 2(1), 23-56.

Sanchis, P. et alli. (2001). Fieis e cidadãos. Percursos de sincretismo no Brasil. Rio de Janeiro: EDUERJ.

Scarparo, H. (2011). Faculdade de Psicologia da Pontifícia Universidade Católica do Rio Grande do Sul (FAPSI/PUCRS). In A. M. Jacó-Vilela (Org.), Dicionário Histórico de Instituições da Psicologia no Brasil. (pp. 211-213). Rio de Janeiro: Imago: Brasília, DF: Conselho Federal de Psicologia.

Schwarcz, L. M. (1993). O espetáculo das raças: cientistas, instituições e questão racial no Brasil - 1870-1930. São Paulo: Cia das Letras.

Schwarz, R. (1977). Ao vencedor as batatas. São Paulo: Duas Cidades.

Velho, G. (1981). Individualismo e cultura. Rio de Janeiro: Zahar.

Velho, L. G. (1905). Do degenerado e sua capacidade civil. Tese de doutorado, Faculdade de Medicina, Rio de Janeiro, RJ. 